\title{
РАЗРАБОТКА УНИВЕРСАЛЬНОГО ПРЕССА ДЛЯ ПРОИЗВОДСТВА РАСТИТЕЛЬНОГО МАСЛА*
}

\author{
V.N. Nevzorov, I.V. Matskevich, \\ V.N. Kholopov, A.V. Kolomeitsev
}

\section{THE DEVELOPMENT OF UNIVERSAL PRESS FOR PRODUCING VEGETABLE OIL}

\begin{abstract}
Невзоров В.Н. - д-р с.-х. наук, проф., зав. каф. технологии, оборудования бродильных и пищевых производств Красноярского государственного аграрного университета, г. Красноярск.

E-mail: nevzorov1945@mail.ru
\end{abstract}

Мацкевич И.В. - канд. техн. наук, ст. преп. каф. технологии, оборудования бродильных и пищевых производств Красноярского государственного аграрного университета, г. Красноярск.

E-mail: IMatskevichV@mail.ru

Холопов В.Н. - д-р техн. наук, профр. каф. автомобилей и транспортно-технологических машин Института лесных технологий Сибирского государственного университета науки и технологий им. акад. М.Ф. Решетнева, г. Красноярск.

E-mail: Holopov1941@yandex.ru

Коломейцев А.B. - канд. биол. наук, доц., начальник управления науки и инноваций Красноярского государственного аграрного университета, г. Красноярск.

E-mail: avk1978@list.ru

Цель исследований - разработка технологии двухэтапного прессования мелкосеменного растительного сырья и разработка универсального пресса для выполнения технологических процессов двухэтапного прессования. Объектом исследования для производства растительных масел и жмыха является разработка технологии двухэтапного холодного прессования с использованием универсального пресса для поэтапного прессования семян и жмыха. Обработка экспериментальных данных производилась статистическими методами. Обоснование разработки новой конструкции масло-пресса базировалось на изучении технического уровня серийно выпускаемых прессов в современном производстве, а также выполненных патентных исследований по
Nevzorov V.N. - Dr. Agr. Sci., Prof., Head, Chair of Technology, Equipment of Fermentative and Food Production, Krasnoyarsk State Agrarian University, Krasnoyarsk.

E-mail: nevzorov1945@mail.ru

Matskevich I.V. - Cand. Techn. Sci., Senior Lecturer, Chair of Technology, Equipment of Fermentative and Food Production, Krasnoyarsk State Agrarian University, Krasnoyarsk.

E-mail: IMatskevichV@mail.ru

Kholopov V.N. - Dr. Techn. Sci., Prof., Chair of Cars and Transport Technological Machines, Institute of Forest Technologies, Siberian State University of Science and Technologies named after Acad. M.F. Reshetnev, Krasnoyarsk.

E-mail: Holopov1941@yandex.ru

Kolomeytsev A.V. - Cand. Biol. Sci., Head, Department of Science and Innovations, Krasnoyarsk State Agrarian University, Krasnoyarsk.

E-mail:avk1978@list.ru

российской и зарубежным инфформационным базам, которые позволили ссрормировать общие принципы, предъявляемые к дальнейшей модернизации масло-прессового оборудования, а также подобрать аналог и прототип для разработки научно-технической документации и офрормления заявки на изобретение. Исследованы технологические процессы производства растительного масла из мелкосеменного растительного сырья, которые позволили получить оптимальные технологические параметры, влияющие на выход высококачественного растительного масла за счет обеспечения сохранения эруковой кислоты в процессе производства масла при заданных технологических параметрах процесса и обеспечения снижения остаточной масличности в жмыхе.

*Проект «Разработка, изготовление и испытание опытного образца универсального пресса для производства рапсового, рыжикового, и горчичного масел» проведен при поддержке Красноярского краевого фронда науки. 
На базе выполненных научных исследований были сформированы основные требования к новой конструкции универсального пресса для мелкосеменного масличного сырья. По результатам разработки конструкторскотехнологической документации на новую конструкцию универсального пресса и подачи заявки на регистрацию авторского права получен патент Российской Федерации № 192240 «Гидравлический пресс для масличного сырья».

Ключевые слова: масличное мелкосеменное сырье, гидравлический пресс, растительное масло, технологический процесс, патентные исследования, патент Российской Федерации.

The purpose of the researches was the development of technology of two-stage pressing of small seed vegetable raw materials and the development of a universal press for the performance of technological processes of two-stage pressing. The object of the research was the development of technology of two-stage cold pressing with using universal press for stage-by-stage pressing of seeds and oil cake for the production of vegetable oil and oil cakes. The processing of experimental data was made by statistical methods. The justification of the development of a new design of oil press was based on studying technological level of serialIy let out press in modern production, and also executed patent researches on Russian and foreign information bases which allowed creating general principles shown to further modernization oil- press equipment, and also to pick up analog and a prototype for the development of scientific and technical documentation and registration of the demand for the invention. Technological processes of production of vegetable oil of small seed vegetable raw materials which allowed receiving optimum technological parameters influencing the exit of highquality vegetable oil due to ensuring preservation of erucic acid in the course of production of oil at the set of technological parameters of the process and ensuring the decrease in residual oil content in oil cake were investigated. On the basis of executed scientific researches the main requirements to a new design of a universal press for small seed olive raw materials was created. According to the results of the development of design-technology documen- tation on a new design of a universal press and application for registration of copyright the patent of the Russian Federation No. 192240 "A hydraulic press for olive raw materials" has been received.

Key words: oilseed small-seed raw materials, hydraulic press, vegetable oil, technological process, patent research, patent of the Russian Federation.

Введение. В последние годы спрос на масличное сырье в Российской Федерации и на мировом рынке стремительно возрастает, что обуславливает необходимость увеличения объемов производства масличных культур, таких как рапс, рыжик и горчица. Для Сибирского федерального округа с его почвенно-климатическими условиями рапс является одной из перспективных масличных культур, посевные площади которого непрерывно возрастают, по данным [1] лидерами по посевным площадям ярового рапса в 2018 г. являются: Кемеровская область с площадью 264154 га, Алтайский край с площадью 17767 га и Красноярский край с площадью 17299 га. Площади, занятые под посев озимого рапса, значительно ниже: в Алтайском крае 2566 га, в Красноярском крае - 992 и в Омской области - 660 га.

Ежегодный рост посевных площадей, урожайности и валового сбора ярового и озимого рапса в хозяйствах различных организационноправовых форм собственности потребовал развития мощностей по переработке семян на масло и жмых. Основным технологическим оборудованием для производства масла и жмыха являются маслопрессы различных конструкций, способов прессования и различной производительности.

При отжиме масла из семян рапса на Российских серийно-выпускаемых маслопрессах марки ПХП-200, М8-МПШ, МП-68, МП-90 и других используют семена с диапазоном влажности 7-10 \%, при переработке более сухих семян рапса требуется предварительное увлажнение водой, а при переработке более влажных семян необходимо произвести предварительное подсушивание в специализированных жаровнях. Процесс экстракции масла происходит при температуре $40-50{ }^{\circ} \mathrm{C}$, температура жмыха на выходе из камеры прессования составляет 
40-95 ${ }^{\circ} \mathrm{C}$, причем остаточная масличность жмыха при использовании отечественного технологического оборудования составляет от 9 до $15 \%[2-4,7]$.

Среди зарубежных марок наиболее известны маслопрессы немецкой фрирмы Florapower и Farmet (Чехия) различных модификаций, которые обеспечивают остаточную масличность жмыха от 7 до $12 \%$ [2-4].

По результатам выполненного анализа существующих технологических схем производства рапсового масла и конструкций используемых маслопрессов была разработана новая технология производства рапсового масла на универсальном прессе двухэтапного типа. На первом этапе прессования мелкосеменного сырья влажностью 7-10 \% осуществляется в шнековом прессе при температуре $40-50{ }^{\circ} \mathrm{C}$ отжим масла и доставка его в приемную емкость. Полученный жмых после первичного этапа прессования имеет температуру $50-80^{\circ} \mathrm{C}$ на выходе, сразу поступает на второй этап прессования в специально разработанный гидравлический пресс, где выполняется второй этап прессования при давлении 30-40 МПа и окончательный отжим масла из жмыха, в котором остаточное содержание масла составляет 3-5 \%.

Преимущество двухэтапной технологии прессования мелкосеменного растительного сырья заключается в увеличении объемов отжатого масла за счет снижения остаточного содержания масла в жмыхе, что дает возможность расширения составления рационов питания при кормлении сельскохозяйственных животных и птицы. Данные преимущества были получены с использованием новой конструкции универсального маслопресса, выполненного на уровне изобретений, что подтверждается патентом Российской Федерации.

Цель исследований: разработка технологии двухэтапного прессования мелкосеменного растительного сырья и разработка универсального пресса для выполнения технологических процессов двухэтапного прессования.

Объект и методы исследований. Объектом исследования для производства растительных масел и жмыха является разработка технологии двухэтапного холодного прессования с исполь- зованием универсального пресса для поэтапного прессования семян и жмыха.

Были проведены патентные исследования по российской и зарубежной информационным базам, выбор аналога и прототипа для разработки универсального маслопресса.

Обработка экспериментальных данных производилась статистическими методами.

Результаты исследований и их обсуждение. Результаты анализа научно-технической литературы и выполненных научных исследований показали, что рапс является одной из наиболее ценных и перспективных культур в общемировом производстве растительных масел. В Сибири семена рапса имеют высокую масличность (40-45 \%) и являются важным источником пищевого растительного масла, а также жмыха, который содержит до 35-40 \% ценного белка и используется в качестве добавки в рецептуре комбикормов для кормления сельскохозяйственных животных и птицы [5].

Рапсовое масло богато жирными кислотами, входящими в состав триацилглицеринов, состав которых повышает устойчивость масла к окислению, что, в свою очередь, позволяет гарантировать производителям рапсового масла для пищевых целей больший срок годности к употреблению. Результаты анализа научнотехнической информации показали, что важным показателем для рапсового масла является наличие эруковой кислоты, минимизация эруковой кислоты в масле играет важную роль при использовании масла в пищевой промышленности. Установлено, что для пищевой промышленности необходимо использовать семена рапса с содержанием эруковой кислоты не более $2 \%$ и глюкозинулатов - $3 \%[3,4]$.

Сорта масла, которые непригодны для пищи из-за повышенного содержания эруковой кислоты и суммарной вместительностью мононенасыщенных кислот в пределах 53-69 \%, а полиненасыщенных - до $23 \%$, используются для производства альтернативного топлива для дизельных двигателей $[3,5]$.

Разработанная технологическая схема двухэтапного холодного прессования масличных семян приведена на рисунке 1. 


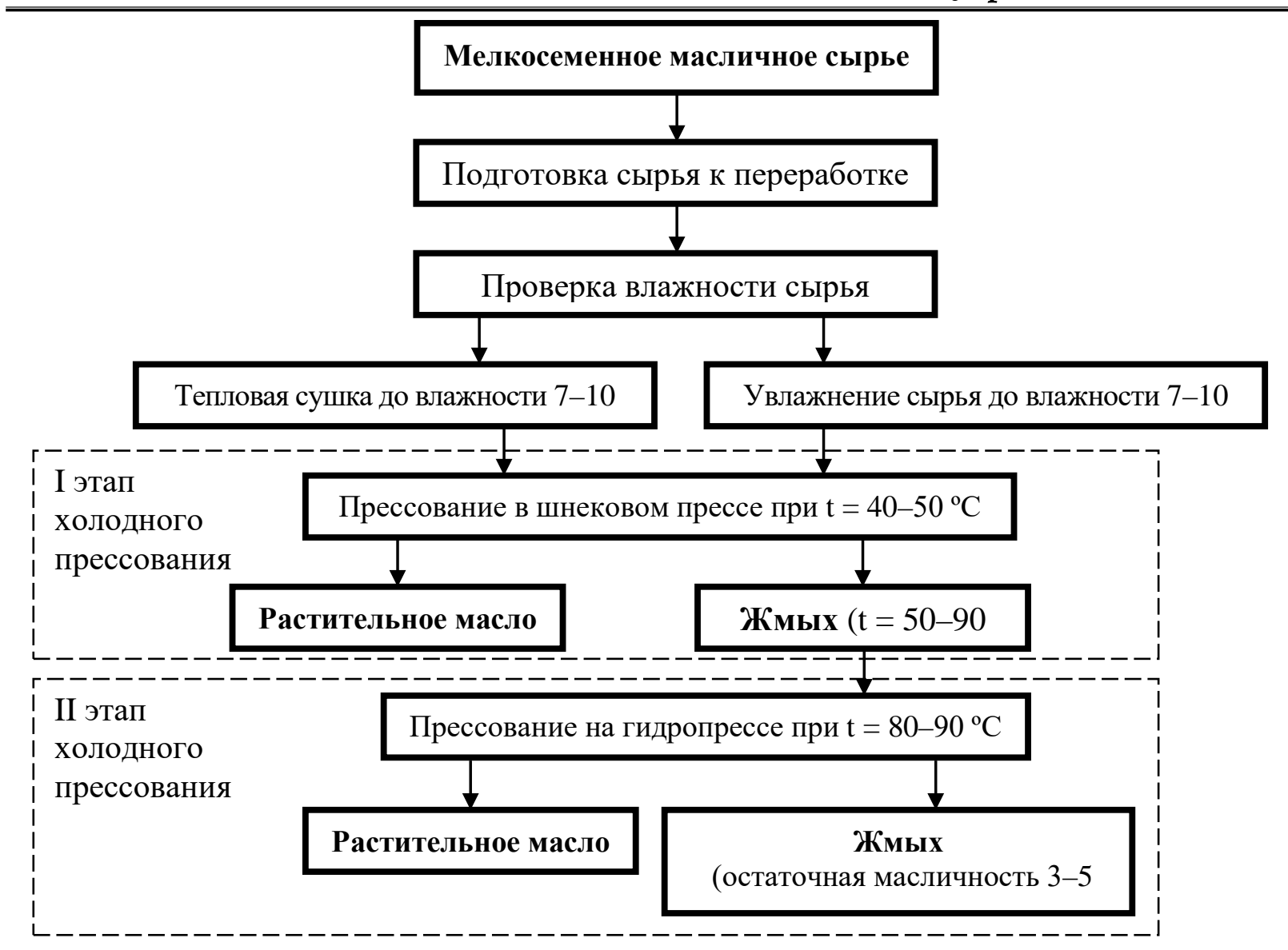

Puc. 1. Технологическая схема двухэтапного холодного прессования масличных семян

Для реализации технологического процесса производства растительного масла методом холодного прессования по разработанной технологической схеме, представленной на рисунке 1, разработана конструкция нового универсального маслопресса, предназначенного для холодного двухэтапного прессования мел- косеменного растительного сырья, кинематическая схема которого приведена на рисунке 2. Авторские права на разработанную конструкцию защищены патентом Российской Федерации № 192240 «Гидравлический пресс для масличного сырья» [4]

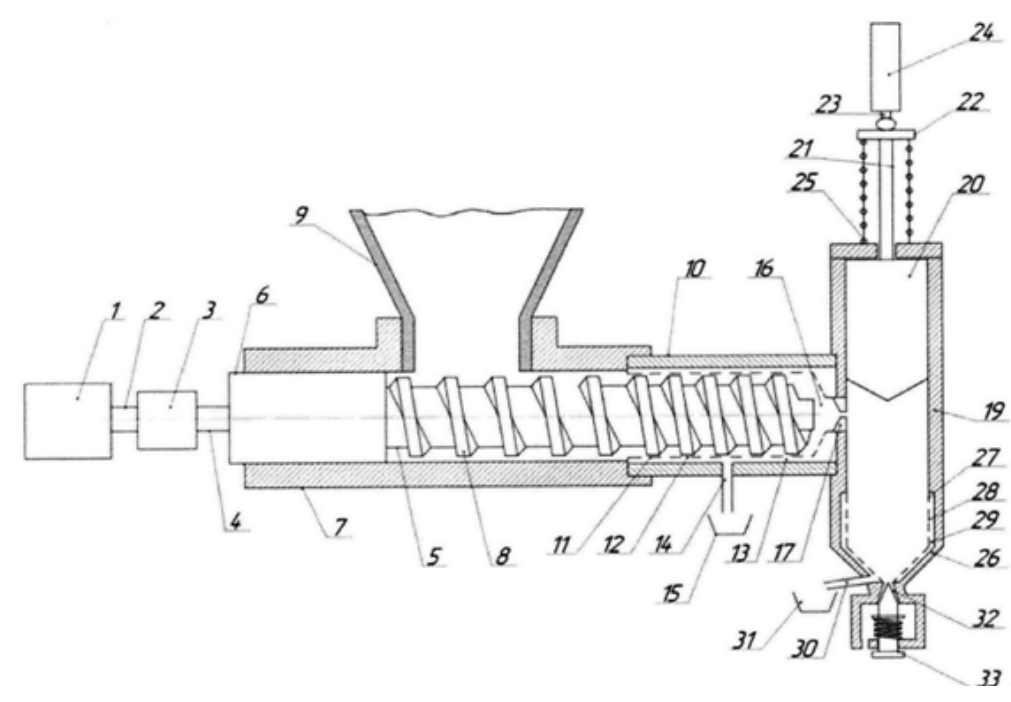

Puc. 2. Гидравлический пресс для масличного сырья 
Гидравлический пресс для масличного сырья работает следующим образом: включается в работу гидромотор 1, который валом 2 через гидрораспределитель 3 передает крутящий момент на приводной вал 4 шнека 5, установленный в опоре 6 корпуса 7. В загрузочный бункер 9 загружается масличное сырье, и шнек 5 винтовой навивкой 8 перемещает его в корпус первичного прессования 10. За счет установки на выходе из корпуса первичного прессования 10, запорного кольца 17 с отверстиями 18 происходит процесс сжатия семян масличного сырья с выделением масла, которое стекает через отверстия 12 решета 11 в масляный канал 13 и далее через патрубок 14 собирается в маслосборник 15. Жмых после первичного прессования поступает через отверстия 18 запорного кольца 17 в корпус вторичного прессования 19. При этом за счет положения гидрораспределителя 3 конусный плунжер 20 находится в верхнем положении. При наполнении объема корпуса вторичного прессования 19 создается усилие для вращения шнека 5, и гидрораспределитель 3 переключается в режим вторичного прессования, при этом привод шнека 5 отключается.

При переключении гидрораспределителя 3 в режим вторичного прессования давление подается на гидроцилиндр 24, который штоком 23 давит на опорную пяту 22, при этом происходит сжатие пружины растяжения 25, и шток 21 давит на плунжер 20, перемещая его в нижнее положение, сжимая при этом масличное сырье, находящееся в корпусе вторичного прессования
19. По мере перемещения конусного плунжера 20 до конуса 26 корпуса вторичного прессования 19 происходит сжатие жмыха и остаточное выделение масла, которое через отверстия 28 решета 27 стекает по масленому каналу 29 через патрубок 30 в маслосборник 31. Полученный жмых выходит через отверстие 32, давление, создаваемое в корпусе вторичного прессования 19, регулируется устройством 33. После того как конусный плунжер 20 переместится в нижнее положение, гидрораспределитель 3 переключается в режим первичного прессования, а пружина растяжения 25 возвращает опорную пяту 22, а вместе с ней конусный плунжер 20 возвращается в исходное состояние, и цикл прессования повторяется.

Результаты лабораторных исследований по обоснованию конструктивных параметров для изготовления опытного образца показали, что остаточная масличность жмыха во многом зависит от радиального зазора диаметра витков шнека и корпуса маслопресса. Установлено, что для получения выходного параметра остаточной масличности в жмыхе в размере 5-7 \% зазор нового шнека с корпусом подчиняется математической зависимости вида

$$
g=0,302+0,00076 d-6,825 \text { (при } r=0,98),(1)
$$

где $g$ - зазор между витком шнека и корпусом маслопресса, мм; d - диаметр шнека, мм.

Графически математическая зависимость (1) представлена на рисунке 3.

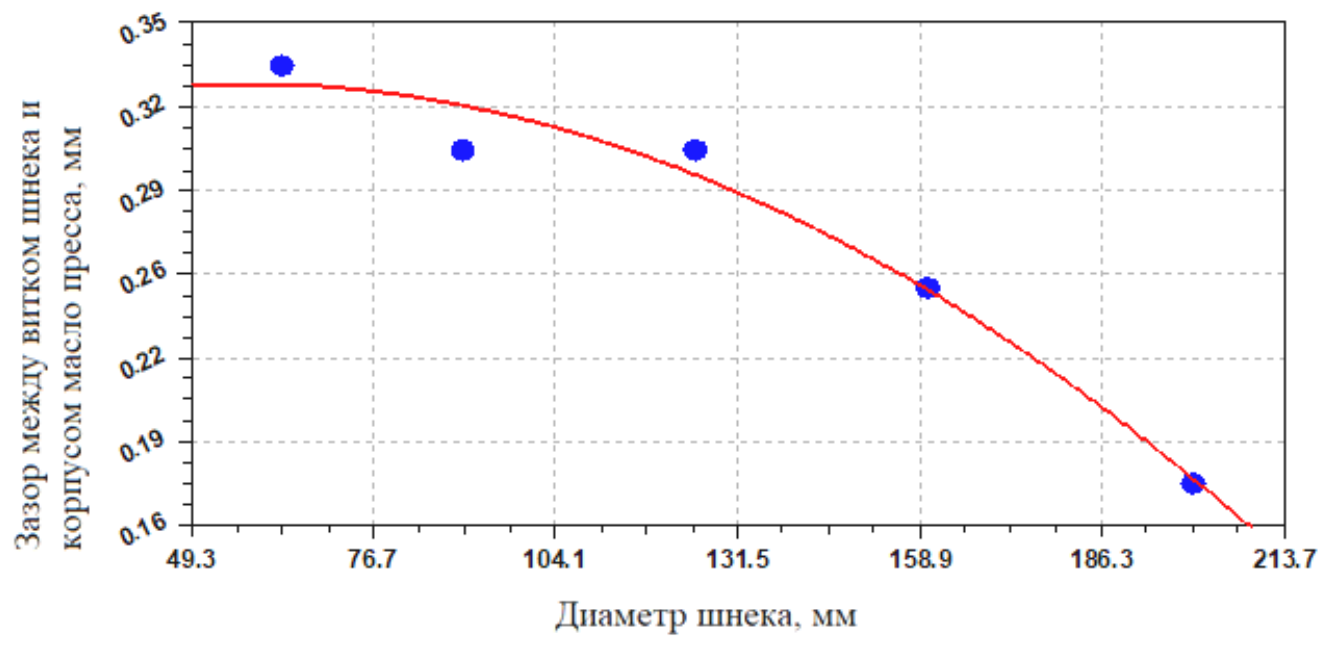

Puc. 3. График изменения зазора между витком шнека и корпусом маслопресса при эксплуатации нового шнека 
Анализ математической зависимости (1) изменения зазора между витком шнека и корпусом маслопресса в зависимости от диаметра шнека показал, что выходной параметр остаточной масличности в жмыхе 5-7 \% достигается при образовании зазора, равного 0,33 мм.

При дальнейшей работе маслопресса происходит увеличение зазора между витками шнека и корпусом маслопресса, при этом увеличиваются выходные параметры остаточной маслич- ности в жмыхе до 7-9 \%, что подчиняется математической зависимости вида

$$
g=0,347+0,0014 d-1,0402 \text { (при } r=0,98),(2)
$$

где $\mathrm{g}$ - зазор между витком шнека и корпусом маслопресса, мм; d - диаметр шнека, мм.

Графически математическая зависимость (2) представлена на рисунке 4.

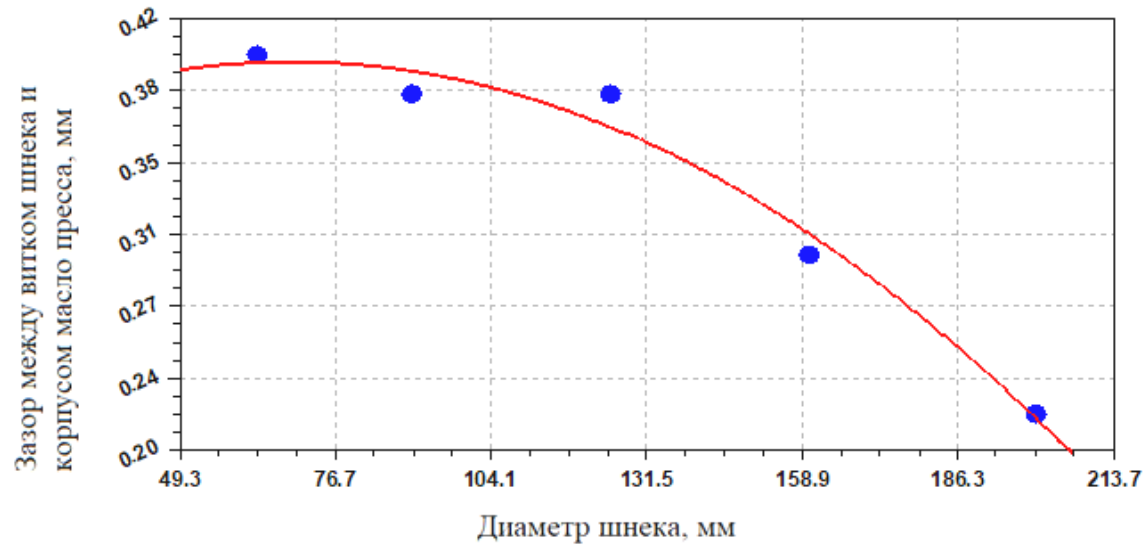

Puc. 4. График влияния диаметра шнека на изменения зазора между витком шнека и корпусом маслопресса

Анализ математической зависимости (2) изменения зазора между витком шнека и корпусом маслопресса в зависимости от диаметра шнека показал, что выходной параметр остаточной масличности в жмыхе 7-9 \% достигается при образовании зазора, равного 0,4 мм.

Дальнейшая эксплуатация маслопресса приводит к увеличению зазора между витком шнека и корпусом маслопресса, при этом увеличиваются выходные параметры остаточной маслич- ности в жмыхе до 9-11 \%, что подчиняется математической зависимости вида

$$
g=0,0879+0,0145 d-6,214 \text { (при } r=0,9) \text {, }
$$

где $g$ - зазор между витком шнека и корпусом масло пресса, мм; d - диаметр шнека, мм.

Графически математическая зависимость (3) представлена на рисунке 5.

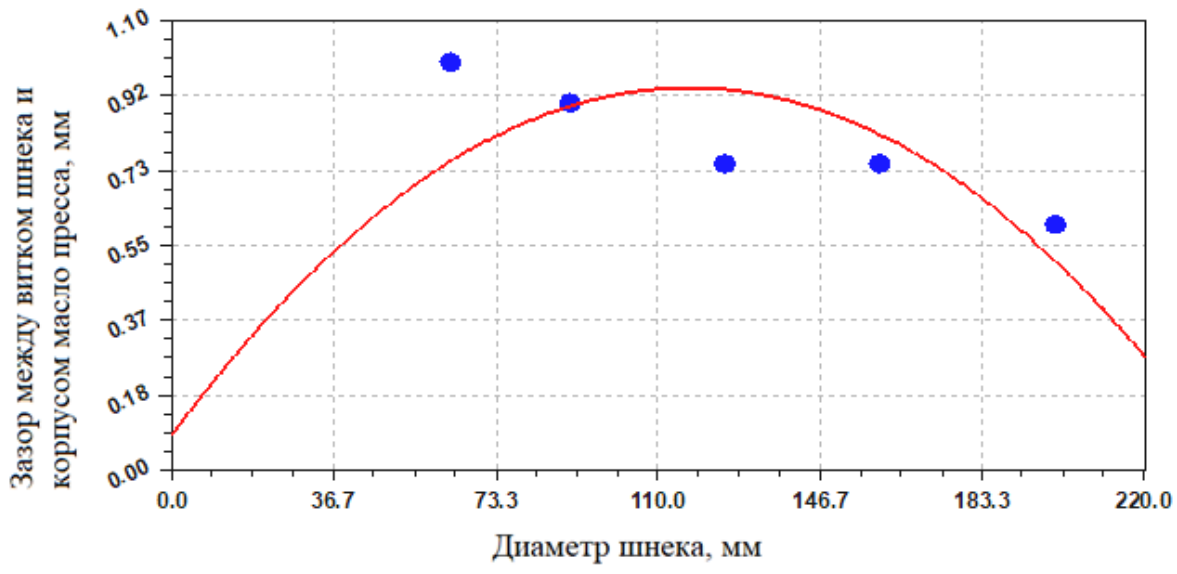

Puc. 5. Графрик зависимости зазора между витком шнека и корпусом маслопресса от диаметра шнека при продолжительной эксплуатации шнека 
Анализ математической зависимости (3) изменения зазора между витком шнека и корпусом маслопресса в зависимости от диаметра шнека показал, что выходной параметр остаточной масличности в жмыхе 9-11 \% достигается на конечном этапе изнашивания рабочих поверхностей маслопресса и конечный показатель зазора равен 1,0 мм.

В процессе эксплуатации маслопресса происходит увеличение зазора между витком шнека и корпусом маслопресса, при этом увеличи- ваются выходные параметры остаточной масличности в жмыхе до 11-14 \%, что подчиняется математической зависимости вида

$$
g=0,1263+0,0157 d-6,6510 \text { (при } r=0,84),(4)
$$

где $g$ - зазор между витком шнека и корпусом маслопресса, мм; d - диаметр шнека, мм.

Графически математическая зависимость (4) представлена на рисунке 6.

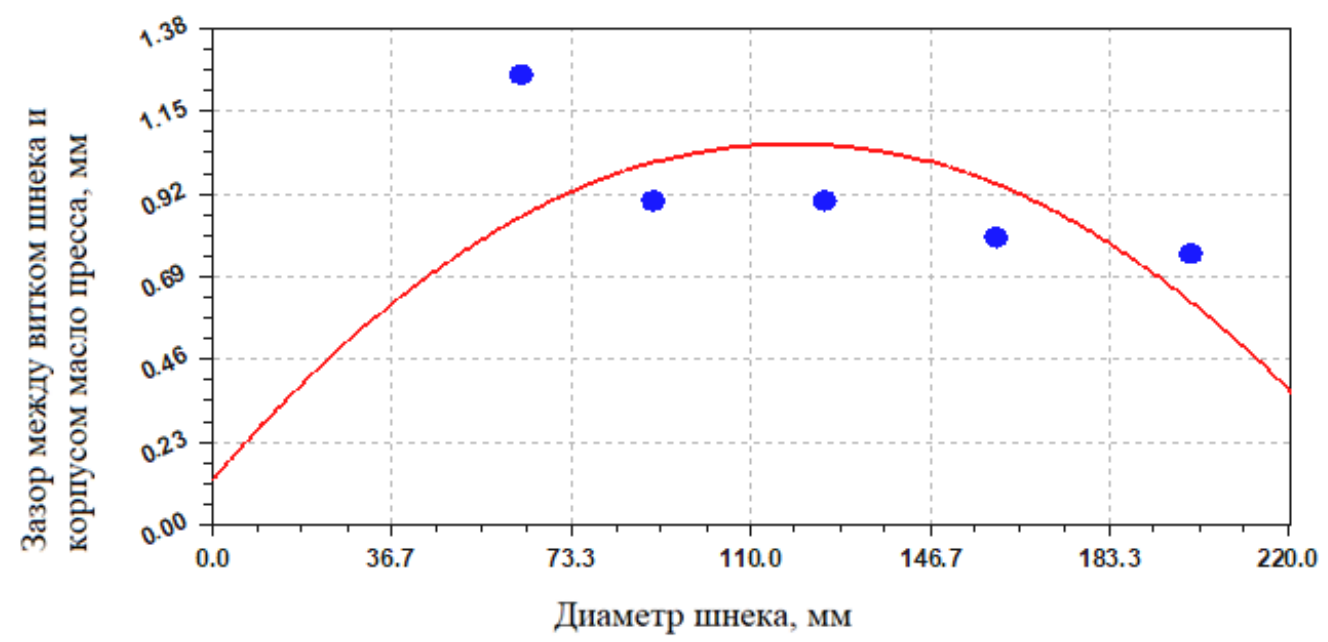

Puc. 6. График изменения зазора между витком шнека и корпусом маслопресса в зависимости от диаметра шнека при длительной эксплуатации маслопресса

Анализ математической зависимости (4) изменения зазора между витком шнека и корпусом маслопресса в зависимости от диаметра шнека показал, что выходной параметр остаточной масличности в жмыхе 11-14 \% достигается на конечном этапе изнашивания рабочих поверхностей маслопресса, зазор равен 1,25 мм, при этом дальнейшая эксплуатация маслопресса приводит к увеличению зазора в трущейся паре и соответственно к резкому увеличению остаточной масличности в жмыхе до 18-20\%, это доказывает, что экономически нецелесообразно производить дальнейшую эксплуатацию маслопресса.

\section{Выводы}

1. Увеличение спроса на масличное сырье на российском и мировом рынках привело к росту объемов масличных культур, что потребовало развития новых производственных мощностей по переработке семян рапса рыжика и горчицы на масло и жмых.
2. Серийно выпускаемые маслопрессы российских и зарубежных марок обеспечивают остаточную масличность жмыха от 7 до $15 \%$, что снижает экономическую эфффективности используемого оборудования.

3. Выполненные патентные исследования позволили определить аналог и прототип для разработки новой конструкции маслопресса, авторские права на техническое решение защищены патентом Российской Федерации № 192240 «Гидравлический пресс для масличного сырья».

4. Разработана технология холодного двухэтапного прессования с использованием нового универсального пресса для масличных культур с остаточным содержанием масла в жмыхе 3-5 \%.

5. Результаты исследований по изменению влияния зазора между витком шнека и корпусом маслопресса позволили построить математические аналитические зависимости, использование которых дает возможность определять остаточное содержание масла в жмыхе при различных величинах зазора. 


\section{Литература}

1. URL: https://сельхозпортал.pqp/analiz-posevnyh-ploshchadej/?area=15.

2. Голубев И.А., Шванская И.А. Оборудование для переработки масличных культур: каталог. - М.: Росинфрормагротех, 2008.

3. Земсков В.И., Александров И.Ю. Производство растительных масел в условиях сельскохозяйственных предприятий малой мощности: учебное пособие. - СПб.: Лань, 2018. $252 \mathrm{c}$.

4. Лобова T.B., Субботина М.A. Рапс - перспективная культура Сибири // Новая наука: опыт, традиции, инновации: мат-лы междунар. науч.-практ. конф. (12 сентября 2016 г., г. Омск). - Стерлитамак: АМИ, 2016. C. 82-84.

5. Олейникова Е.Н., Янова М.А., Пьжикова Н.И. и др. Яровой рапс - перспективная культура для развития агропромышленного комплекса Красноярского края // Вестн. КрасГАУ. 2019. - № 1.

6. Пат. ПМ №192240 Российская Федерация, МПК В30В 9/02, С11В1/06. Гидравлический пресс для масличного сырья / Невзоров В.Н., Холопов В.Н., Мацкевич И.В., Коломейцев A.B.; заявитель и патентообладатель ФГБОУ ВО «Красноярский государственный аграрный университет». - № 2019120744; заявл. 01.07.2019; опубл. 09.09.2019, Бюл. № 25. $-5 \mathrm{C}$.

7. Самойлов В.А. и др. Научные исследования пищевого технологического оборудования на основе патентных разработок: метод. указания для практических работ / Краснояр. гос. аграр. ун-т. - Красноярск, 2012. - 63 с.
Literatura

1. URL: https://sel'hozportal..f/analiz-posevnyhploshhadej/?area=15.

2. Golubev I.A., SHvanskaya I.A. Oborudovanie dlya pererabotki maslichnyh kul'tur: katalog. M.: Rosinformagrotekh, 2008.

3. Zemskov V.I., Aleksandrov I.Yu. Proizvodstvo rastitel'nyh masel $v$ usloviyah sel'skohozyajstvennyh predpriyatij maloj moshchnosti: uchebnoe posobie. - SPb.: Lan', 2018. - $252 \mathrm{~s}$.

4. Lobova T.V., Subbotina M.A. Raps perspektivnaya kul'tura Sibiri // Novaya nauka: opyt, tradicii, innovacii: mat-ly mezhdunar. nauch.-prakt. konf. (12 sentyabrya 2016 g., g. Omsk). - Sterlitamak: AMI, 2016. - S. 82-84.

5. Olejnikova E.N., Yanova M.A., Pyzhikova N.I. idr. Yarovoj raps - perspektivnaya kul'tura dlya razvitiya agropromyshlennogo kompleksa Krasnoyarskogo kraya // Vestn. KrasGAU. 2019. - № 1.

6. Pat. PM № 192240 Rossijskaya Federaciya, MPK V30V 9/02, S11V1/06. Gidravlicheskij press dlya maslichnogo syr'ya / Nevzorov V.N., Holopov V.N., Mackevich I.V., Kolomejcev A.V.; zayavitel' i patentoobladatel' FGBOU VO «Krasnoyarskij gosudarstvennyj agrarnyj universitet». - № 2019120744; zayavl. 01.07.2019; opubl. 09.09.2019, Byul. № 25. - $5 \mathrm{~s}$.

7. Samojlov V.A. i dr. Nauchnye issledovaniya pishchevogo tekhnologicheskogo oborudovaniya na osnove patentnyh razrabotok: metod. ukazaniya dlya prakticheskih rabot / Krasnoyar. gos. agrar. un-t. - Krasnoyarsk, 2012. - 63 s. 